\title{
Achieving advantages from business-to-business electronic commerce: an empirical validation of an integrative framework
}

\author{
Koffi N'Da* \\ Department of Decision Sciences \\ and Management Information Systems, \\ E. Philip Saunders College of Business, \\ Rochester Institute of Technology, \\ Rochester, New York 14623, USA \\ Fax: (585) 475-5975 \\ E-mail:knda@saunders.rit.edu \\ ${ }^{*}$ Corresponding author
}

\section{François Bergeron}

Département Travail, Economie et Gestion, Télé-université, Université du Québec à Montréal, 455, rue du Parvis, Québec, Québec, G1K 9H5, Canada

E-mail: bergeron.francois@teluq.uqam.ca

\section{Louis Raymond}

Département des sciences de la gestion, Université du Québec à Trois-Rivières, Trois-Rivières, Québec, G9A 5H7, Canada Fax: (819) 376-5079Ｅ-mail: louis.raymond@uqtr.ca

\begin{abstract}
This study aims at contributing to a better understanding of business-to-business Electronic Commerce (EC) advantages and determinants of these advantages. A research model was empirically tested on a sample of 143 Canadian companies. Key findings indicate that the most important advantages of EC are increased productivity, increased quality of products and services, competitive advantage, and to a lesser extent, sales growth and increased revenues. Cost reductions were marginal. The main determinants of EC advantages include the type of EC use, and the internal and external integrations of EC applications. The strategic orientation of the firm and the organisational context exert only an indirect effect on EC advantages.
\end{abstract}

Keywords: EC; electronic commerce; e-commerce; electronic business; e-business; B2B; business to business; advantages; strategy; use; integration; organisational context.

Reference to this paper should be made as follows: Koffi, N'Da, Bergeron, F. and Raymond, L. (2008) 'Achieving advantages from business-to-business electronic commerce: an empirical validation of an integrative framework', Int. J. Electronic Business Vol. 6, No. 5, pp.516-549. 


\begin{abstract}
Biographical notes: Koffi N'Da is an Assistant Professor in the Department of Decision Sciences and Management Information Systems at the E. Philip Saunders College of Business, Rochester Institute of Technology. His research interests include e-commerce/e-business, Information Technologies (IT) adoption and use in developing countries, IT adoption and use by minority-owned businesses, and digital entrepreneurship.
\end{abstract}

François Bergeron is Professor of Information Systems at TÉLUQ-UQÀM. His research interests are: Strategic alignment of IT, IT adoption and use, e-business, and the impacts of IT on organisational performance. He has published several papers in information systems journals including MIS Quarterly, Journal of Strategic Information Systems, Journal of Management Information Systems, Information and Management, European Journal of Information Systems, Decision Support Systems, Journal of Information Systems and many others.

Louis Raymond is Professor of Information Systems at the Université du Québec à Trois-Rivières. He is also the holder of the Canada Research Chair on Enterprise Performance. His work has been published in journals such as the Journal of Management Information Systems, MIS Quarterly, Entrepreneurship Theory and Practice, Project Management Journal, Journal of Information Technology and Information Systems Journal. His research areas include: IT use and IT management in small business, alignment of information systems, electronic business, and network enterprise information systems.

\title{
1 Introduction
}

The increasing use of business-to-business Electronic Commerce (EC) to conduct business activities and the resulting organisational changes represent both a major challenge for organisations and a new field of research for researchers in organisation in general (Applegate et al., 1996) and more specifically for researchers in Information Systems (IS).

While organisations implementing EC may have different objectives in terms of productivity, performance, or competitiveness, not all of them attain positive results. It is still difficult for managers to seize the importance of matching the type of EC, be it transactional, informational or strategic, with the business strategy. The organisational context plays a role in EC success, and the questions of technological and systems integration as well as the level of use of EC (in the firm and by business partners) cannot be overemphasised. Yet, a more precise understanding of these critical aspects of EC is required to offer guidelines to organisations who really want to get positive results from these systems. This research investigates the actual advantages that can result from the adoption and use of EC by organisations and aims to identify the determinants of such advantages.

This paper is structured as follows. In the next section, we highlight findings from prior relevant studies on EC. We present the research model and hypotheses in the third section. We describe the research methodology in the fourth section. We present the empirical results of the current study in the fifth section. Then, we discuss these results and their implications in the sixth section. In the seventh section of the paper, 
we highlight some of the limitations of the study. The paper ends with a conclusion in the eighth section.

\section{Background}

In past years, many studies have been devoted to EC (Ngai and Wat, 2002). Findings from these studies have shown that EC adoption and use by organisations can generate various advantages (Pflughoeft et al., 2003; Pires and Aisbett, 2003). EC usage has a significant impact on business performance (Kraemer et al., 2005; Merono-Cerdan and Soto-Acosta, 2005; Ramamurthy and Premkumar, 1995; Shin, 2004; Yao et al., 2002; Wade et al., 2004; Zhu and Kraemer, 2005). EC adoption and use can also lead to cost reductions (Raymond and Bergeron, 1996, 1997; Fruhling and Digman, 2000; Kauffman and Walden, 2001; Elia et al., 2007; Seppanen and Suomala, 2003). Furthermore, EC use can improve the quality of customer services (Margherio et al., 1998; Elia et al., 2007) and products. Additional advantages obtained from EC use include business growth (Porter, 2001; Elia et al., 2007); organisational and interorganisational productivity (Bergeron and Raymond, 1997; Johnston and Vitale, 1988; Teo et al., 1994); and competitive advantage (Amit and Zott, 2001; Chatfield and Yetton, 2000; Chircu and Kauffman, 2000; Ranganathan et al., 2004; Teo and Pian, 2003).

Prior studies have suggested that the business value of Information Technology (IT) depends on various internal and external factors (Melville et al., 2004). As regard to EC advantages more specifically, the literature has shown that they can be affected by factors such as: The EC strategy as well as the business strategy; the use of EC application; top management involvement; users' support and training; the level of security of the EC application; and the level of integration of the EC application with internal systems as well as with business partners systems.

Regarding the relationship between the EC strategy and EC advantages, studies have shown that EC is linked to an improved performance for companies with more explicit EC strategies (Boyer and Olson, 2004). For instance, Koo et al. (2004) have found that Porter's competitive strategies are associated with business performance in electronic markets. In the same vein, a study from Chang et al. (2003) have shown a positive relationship between a firm's perception of $\mathrm{EC}$ as reflected in corporate strategy and the firm's performance. According to Zhuang (2006), different EC strategies lead to different benefits. For example, companies following a differentiation strategy profit from customer service benefits, while cost leadership strategy followers benefit from market expansion.

Concerning the effect of organisational factors on EC advantages, previous studies have established a positive relationship between a strong top management support of EDI and benefits obtained from these systems (Bergeron and Raymond, 1997; Teo et al., 1994). Research has also shown that a visible involvement of the CEO encourages positive attitudes of users with regard to EC systems (Teo and Too, 2000; Teo et al. 1997-1998). The existence of a support team dedicated to system users as well as users' training play a dominating role in the success of an IS because both variables positively influence the use of the system and advantages gained from it (Banerjee and Golhar, 1994; Grover, 1993). The experience with IT has been considered as one of the specific resources that can provide the organisation higher profits and a greater market share if it 
is effectively used (Mata et al., 1995; Ross et al., 1996). Along the same vein, Weill (1992) has shown that prior experience with IT positively influences the relationship between IT investments and the organisational performance. A positive relationship between the experience with the internet and the organisational performance has been highlighted by authors such as Avlonitis and Karayanni (1996).

The effect of EC security on EC advantages has also been investigated. For example, Bergeron and Raymond (1997) have shown that control procedures (integrity of the data and data security) have a positive effect on the advantages generated by EDI. Perceptions of non-repudiation, privacy protection, and data integrity have been found to significantly affect trust in EC, which ultimately has a significant impact on EC acceptance and actual use (Suh and Han, 2003). In fact, EC security is considered by several organisations as one of the most important factors in integrating a new technology such as the internet/web with their existing data-processing infrastructure (Teubner, 1998; Shih and Wen, 2005). According to Liao and Cheung (2002), EC security level is a key determinant of EC use, as well as the advantages these systems provide to the organisation. However, the vulnerabilities of the internet and resulting risks may prevent customers from participating in EC (Strader and Shaw, 1997).

As for the relationship between EC integration and EC advantages, Neo et al. (1994) have concluded that the integration of TradeNet to internal procedures and processes is a significant determinant of both the organisational performance and the organisation's post-adoption effectiveness. The study of Bergeron and Raymond (1997) has also revealed a positive relationship between the level of integration of EDI and the advantages attached to the system. EDI and web-based EC systems benefits have been found to be higher with increased internal integration of the systems (Mukhopadhyay, 1998; Subramaniam and Shaw, 2002). According to Zhu (2004), EC capability (including back-end integration) has a positive relationship to firm performance. A study realised by Frohlich and Westbrook (2002) has concluded that higher levels of performance are associated with higher levels of web-based integration. Claycomb et al. (2005) have demonstrated that EC compatibility with current systems relates positively to the overall use of the system.

Although EC advantages and determinants of these advantages have been investigated by many researchers, many organisations are still unsure whether EC can deliver the expected benefits (Subramaniam and Shaw, 2002) because the literature presents managers an ambiguous and confused picture of the business value resulting from EC adoption (Pires and Aisbett, 2003). According to Tagliavini et al. (2001), the lack of knowledge about EC advantages represents a major obstacle to the use of EC systems by smaller companies. The mixed results of prior studies examining EC advantages can be explained not only by the divergent approaches used by these studies to conceptualise the key constructs and their relationships (Melville et al., 2004), but also by the fact that relatively few empirical studies have provided an integrated framework to explain EC advantages. The scarcity of such frameworks constitutes a major concern for managers adopting EC applications. Generally, managers do not have sufficient knowledge of post-adoption advantages provided by EC (Riggins and Rhee, 1998; Subramanian and Shaw, 2002; Zhu, 2004).

Because of the above limitations related to prior EC research, and considering the sustained growth of EC activities, new empirical studies need to be undertaken. The current study aims at contributing to a better understanding of EC advantages through an integrative framework that have been empirically tested. This research can be 
viewed as aiming to respond to the need expressed by Melville et al. (2004) to undertake more research about which organisation resources are synergistic with which type of IT and in what organisation context. Specific objectives are:

- to investigate the actual advantages that can result from the use of EC by an organisation and its business partners

- to identify the determinants of such advantages.

More specifically, we focus in this study on the role played by the organisational strategy, the organisational context, the type of use and the use of the EC in the generation of EC advantages.

\section{Research model}

The research model is shown on Figure 1. According to this model, five main advantages are provided by EC: growth, increased productivity, products/services quality improvement, cost reduction, and gain of strategic advantage. These advantages are jointly determined by five main endogenous factors, namely the level of use of EC, the strategic orientation of the organisation, the type of EC use, the organisational context, and the level of EC integration. Finally, the research model also stipulates that EC use is determined by the organisation context; the EC integration level, and the type of use, which is related to the strategic orientation.

Figure 1 Research model on the advantages of EC

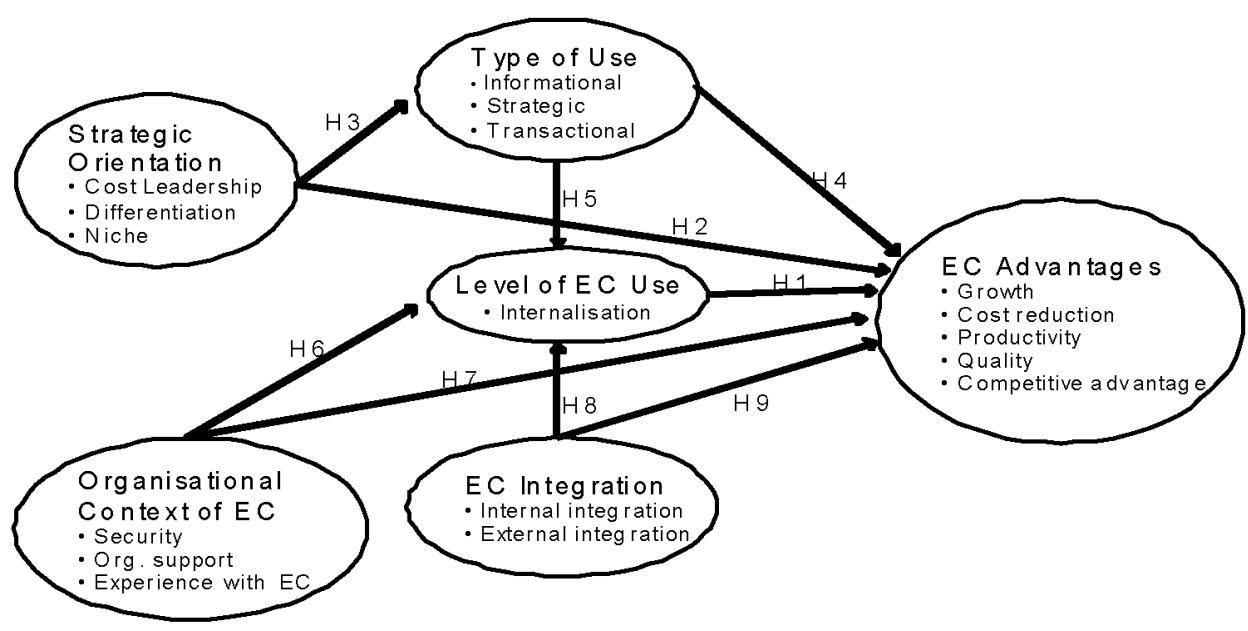

The theoretical base of this research is borrowed from previous conceptual models on the impacts and advantages of IS, and factors that determine those impacts and advantages (Delone and McLean, 1992; Bergeron and Raymond, 1997), as well as models on the use of the web (Koh and Balthazard, 1998). All the variables of the research model are explained in the following sections. 


\subsection{Strategic orientation}

The strategic orientation of the organisation refers to the competitive strategy adopted by the organisation and supported by the EC. Porter's (1980) three generic strategies are used in this study: cost leadership, differentiation and niche strategies. The main objective of an organisation adopting a cost leadership strategy is to obtain lower costs than the competition. The differentiation strategy consists in providing to customers, products and services that are unique and personalised. An organisation with a niche strategy concentrates on a specific target and provides to this target, differentiated or low price products or services.

\subsection{Type of EC use}

The variable type of EC use refers to the variety of uses of EC. This research focuses on three types of EC usages: informational, transactional and strategic. The main objective of an informational EC is to disseminate a variety of information about the organisation, as well as its products and services (Koh and Balthazard, 1998; Nambisan and Wang, 1999). Transactional EC support both direct transactions with customers and electronic payment. Strategic EC primarily aim at allowing an organisation to: increase customers' loyalty, search for alternate suppliers, build strategic alliances with other organisations, innovate and develop new products, reach new markets, and increase the organisation's market share. These three types of EC uses are not mutually exclusive. Indeed, a given EC can combine characteristics from each type of systems.

\subsection{Organisational context}

The organisational context variable refers to the activities, procedures, and assets set by the organisation for the effective implementation and use of EC. It includes the organisational support, the experience with EC as well as the level of security of the system. Organisational support is composed of the top management involvement, the existence of a support team, and the training of system users. EC experience represents the level of previous organisational experience in using the internet and the web for commercial purposes (Mata et al., 1995; Ross et al., 1996). The level of security refers to software and hardware infrastructures and procedures implemented in order to secure business transactions carried out by EC.

\subsection{EC integration}

The level of integration of EC encompasses two components namely, internal integration and external integration. Internal integration refers to the number of administrative and value chains functions or applications incorporated through EC (Bergeron and Raymond, 1997). External integration relates to the number of business partners (customers, suppliers, distributors, government agencies, etc) using EC in their business relationship with the organisation (Bergeron and Raymond, 1997; Bensaou, 1993; Sanders, 1992; Swatman and Swatman, 1991; Zaheer and Venkatraman, 1994). 


\subsection{Level of EC use}

The level of EC use (or EC use) refers to the internalisation of EC. The internalisation of an information system defines its importance for the user in performing his task (Raymond and Bergeron 1997). In the current study, the concept of internalisation can be perceived at two distinctive levels. First, at the organisational level, the internalisation of EC describes how essential the system is for an organisation in achieving its business activities with its partners (customers, suppliers, distributors, etc.). At the business partners' level, the internalisation of EC can be viewed in terms of the necessity for each partner to use EC to carry business transactions with the organisation (Ranganathan et al., 2004).

\subsection{Advantages}

The advantages obtained from the use of EC represent the dependant (exogenous) variable of the research model. This variable encompasses five dimensions: growth, productivity, costs reduction, quality improvement of products and services, and competitive advantage.

Growth. Two categories of growth enabled by EC are considered in this study, increased sales and revenues. An organisation can increase its sales by using EC to create and penetrate new markets, develop new products and services, as well as to build stronger relationships with customers (Fruhling and Digman, 2000; Porter, 2001). In addition, the implementation of EC can increase the number of potential buyers which, in turn can result in an increase in the number of orders and, consequently, sales growth due to EC.

Productivity. The second dimension of EC advantages is productivity, in particular organisational productivity and interorganisational productivity. Organisational productivity reflects the internal productivity gain due to the use of EC, such as the productivity of the personnel. The interorganisational productivity examined in this research refers to the improvement of the communications between the company and its business partners such as fast access to the information, accuracy and timeliness of the information (Johnston and Vitale, 1988; Teo et al., 1994).

Cost reduction. constitutes the third variable of EC advantages. By allowing a direct connection between a company and its business partners, EC can contribute to reduce a variety of costs such as transactions costs, coordination costs, distribution costs, communication costs, publication costs, customers' support costs, advertising and marketing costs, administrative costs, orders handling and management costs, good acquisition costs, and inventory management costs (Bakos, 1991; Wai-Pun et al., 1997).

Quality improvement. The fourth dimension of EC advantages includes products/services quality improvement. The quality of a product (or a service) can be defined as the degree of superiority of the product (or the service) as perceived by the customers, compared to those of the competitors (Segev, 1989). The use of EC constitutes a means for a company to offer products and services of better quality. EC allow customers to access a variety of information and services online, in particular: products/services descriptions; technical support; answers to the Frequently Asked Questions (FAQ); order tracking; customers' accounts access, etc. (Margherio et al., 1998). 
Competitive advantage. The last dimension of EC advantages relates to competitive advantages provided by EC including: the creation of customers' loyalty, the increase of market share, the development of new products and services, as well as the preemptive entry on the market (Sethi and King, 1994). Firms can create customers' loyalty by using EC to establish closer and personalised relationship with customers (Palvia, 1997). EC can help increase market share as it can be used to penetrate new markets and to reach new customers. Organisations can innovate and create new products and services through EC. Finally, EC can allow an organisation to make a preemptive entry on the market by improving the manufacturing process and the marketing of the products/services.

\subsection{Research hypotheses}

\subsubsection{Level of EC use and EC advantages}

EC adoption and use can generate various organisational advantages. These advantages can be internal to the organisation, market-oriented or competitive (Pires and Aisbett, 2003). Internally, the adoption and use of EC by an organisation can lead to increased revenue and profits, growth, increased productivity, as well as increased flexibility and responsiveness. Other internal EC advantages include reduction of costs such as transaction, operation, marketing and distribution costs; economies of scale and accelerated transactions; and increased quality of product. At the market level, the use of EC provide various advantages such as: new markets creation/reach; easy access to business partners; better customer service; closer customer relationship; improved communication; alternate sales/delivery channels; new products creation; and increased efficiency. Competitive advantages gained from EC include: new opportunities offered by EC; increased customer perceived value; and faster products to market. In order to gain most of EC advantages, the organisation must internalise its EC system. As shown by Bergeron and Raymond (1997) regarding EDI, the more the system is internalised, the higher the advantages will be. Therefore, we hypothesise that the level of EC use (internalisation) will positively affect the advantages gained from the system. This leads to the following hypothesis.

H1: There is a positive relationship between the use of EC and the advantages obtained from $E C$.

\subsubsection{Strategic orientation and EC advantages}

EC can be used to support the strategic orientation of the organisation in order to generate various advantages. An organisation pursuing a strategy of differentiation or niche can increase customers' loyalty by improving service and products quality based on customers' data collected through the use of EC. In addition, EC can help an organisation differentiate itself by facilitating innovation, preemptive access and shorter time to market (Bloch et al., 1996). An organisation with a niche strategy can selectively offer new products or services to targeted customers through its EC. This may result in: increasing customers' satisfaction and loyalty, attracting new customers, and ultimately increasing market share. A competitive strategy based on cost leadership can be supported by EC in order to minimise various costs (such as transaction costs, coordination costs, administrative costs, communication costs, etc.) and increase 
organisational and interorganisational productivity. Thus, we expect that the advantages generated by EC will differ according to the strategic orientation of the organisation. Consequently, we formulate the hypothesis below:

H2: The advantages obtained from EC by an organization are related to its strategic orientation.

\subsubsection{Strategic orientation and type of EC use}

Teo and Pian (2003) have found that a proactive business technology strategy is positively associated with the level of internet adoption ranging from e-mail adoption (level 0) to business transformation (level 4). An organisation adopting a cost leadership strategy will favour a transactional and informational use of its EC in order to increase its effectiveness. On the other hand, an organisation having a strategic orientation of differentiation will lean more towards an informational and a strategic use of its EC system in order to retain existing customers and attract new ones. Such an organisisation can also make a transactional use of its EC system in order to provide unique services to its business partners. Finally, an organisation pursuing a strategy of niche may need all types of EC uses to maximise advantages gained from the system. Therefore, we hypothesise that the strategic orientation is associated to the type of use of EC.

H3: The type of EC use is related to the strategic orientation of the organization.

\subsubsection{Type of EC use and EC advantages}

The way the organisation uses EC may determine advantages of the system. Indeed, EC capability, which encompasses information use and transactional use of EC (as well as customisation and back-end integration), exhibits a positive relationship with firm performance (Zhu, 2004). Findings from Pflughoeft et al. (2003) suggest that the use of the web for e-commerce (transactional use) by small businesses is related to both strategic benefits (expressed in terms of market expansion, increasing sales, and improving customer bases) and operational efficiencies (such as reductions in operating costs, productivity, speed of conducting business activities, ability of employees to work away from the office, and the firm's ability to meet customers' needs). Additionally, according to theses authors, use of web for information search (information use) is linked to operational efficiencies.

In the current study, we assume that a transactional use of $\mathrm{EC}$ will provide advantages related to operational activities such as: Increased of both organisational and interorganisational productivity, reduced labour costs, reduced transaction errors and costs, reduced transactions processing time, reduced coordination costs, reduced communication and publication costs and reduced information retrieval costs. Advantages derived from the informational use of EC can be expressed in terms of cost reduction, increased visibility for the organisation, and generation of additional incomes due to incremental sales and advertising from other companies (Koh and Balthazard, 1998). The strategic use of EC will generate advantages such as: increased incomes; increased products and services quality; increased market share; products and services innovation; and preemptive entry on the market (Bergeron and Raymond, 1997). Based on the previous arguments, we state the following hypothesis:

H4: The advantages obtained from EC are related to the type of EC use. 


\subsubsection{Type of EC use and level of EC use}

The type of EC use will exert an influence on the level of use of the system. We anticipate that transactional EC will be internalised by the system's users as these systems are needed to perform daily business processes. Informational EC will also be internalised by users because they provide a variety of information that is essential to the users of the system, such as: the information about the organisation; products and services information; and the information related business transactions and processes. With regard to the strategic EC, their internalisation will depend on the usefulness of their output in the decision making process. The more these outputs are required for decision making, the more the user will internalise EC. Thus, the following hypothesis can be made:

H5: The level of EC use is related to the type of EC use.

\subsubsection{Organisational context of EC, level of EC use and EC advantages}

Findings from prior research have established a strong effect of organisational factors on EC adoption and benefits. The involvement and support of the top management is a key determinant of EC use (Teo and Too, 2000) and advantages (Bergeron and Raymond, 1997). Setting a support team devoted to the system and training the system's users affect the use of EDI and advantages derived from the system (Bergeron and Raymond, 1997). Experience with the internet has a positive effect on organisational performance (Avlonitis and Karayanni, 1996). EC security level is a key determinant of EC use, as well as the advantages gained from these systems (Liao and Cheung, 2002). We therefore postulate that:

H6: There is a positive relationship between the organisational context of EC and the level of EC use.

H7: There is a positive relationship between the organisational context of EC and the advantages obtained from $\mathrm{EC}$.

\subsubsection{EC integration, level of EC use and EC advantages}

EC integration with existing internal systems and business partners is an important factor that influences both EC use and advantages. EC Integration is observed when a business information system allow various business functions to communicate to each other seamlessly, by the use of a common database, common architecture and infrastructure, and appropriate interfaces. The compatibility of EC with current systems can positively affect the overall use of the system (Claycomb et al., 2005). Pflughoeft et al. (2003) have suggested that the electronic integration of the firm with its customers and suppliers and other stakeholders tends to generate strategic and operational benefits. EC benefits can be higher with increased internal integration such as purchasing, ordering, accounting, billing, and shipping/delivery and increased external integration with business partners such as customers, suppliers, distributors, banks, government agencies, etc (Subramaniam and Shaw, 2002). We consequently anticipate that a higher integration of EC to internal and external business activities will lead to both a higher level of use (internalisation) of the system and higher advantages for the organisation. 
H8: There is a positive relationship between the integration of EC and the level of EC use.

H9: There is a positive relationship between the integration of EC and the advantages obtained from $\mathrm{EC}$.

\section{Research methodology}

\subsection{Measurement}

Strategic Orientation. Nineteen items measured the strategic orientation of the organisation, including eight for the cost leadership strategy, eight for differentiation strategy, and three for the niche strategy. For each item, respondents were asked to indicate the importance their organisation attached to the underlying strategic activities on a five point Likert with values ranging from "Not at all important" to "Extremely important".

Type of EC Use. The informational and transactional types of use were measured using an instrument developed by Koh and Balthazard (1998). Measures for the strategic type of use were adapted from previous studies (McKeen and Smith, 1993). Each type of EC use item was measured on a five point Likert scale with values ranging from 'strongly disagree' to 'strongly agree'. A total of 27 items measured the type of EC use including: Nine items for the informational use, 13 for the transactional use, and five items for the strategic use.

Organisational Context of EC. The instrument measuring the organisational support variable is an adaptation of the one designed by Bergeron and Raymond (1997). In total, eleven items were involved in the organisation support measurement: Three items were related to the top management support; three items were attached to the support team; and five items dealt with the users' training. Each item was assessed using a five point Likert scale with values from 'strongly disagree' to 'strongly agree'. The experience with EC and internet technologies variable was measured using one quantitative item, (as has been done in prior research, Bergeron and Raymond, 1997), asking for how long (in months) the organisation has been using internet and EC technologies for commercial purposes. For the measurement of EC security level, the authors designed an instrument adapted from Bergeron and Raymond (1997). This instrument included ten items measuring five dimensions of EC security: data integrity (three items), data confidentiality (four items), users/business partners' authentication (one item), and non-repudiation ( 2 items). Each item was assessed using a five point Likert scale with values ranging from 'strongly disagree' to 'strongly agree'.

Integration of $E C$. The internal integration variable was measured in two ways. First, the respondent was asked to check (enumerating) all internal applications integrated to EC. Then, he or she was asked to globally assess the level of internal integration of EC according to a five point Likert scale with values from 'very low' to 'very high'. Similarly, the external integration of EC was measured following the two-way path. The respondent was first requested to indicate the proportion (percentage) of business partners connected to the organisation's EC (see questionnaire). He or she was then asked to globally assess the level of external integration of EC based on a five point Likert scale 
with a range of values from 'very low' to 'very high'. A total score for the level of integration was obtained by calculating the average on all scales.

Level of EC Use. The use of EC was measured in terms of frequency of use, by two quantitative data items: the monthly average time of EC use by the internal users, and the monthly average time of EC use by business partners. The measurement of EC internalisation was adapted from the instrument developed by Bergeron et al. (1995). This adapted instrument comprised six items individually measured through a five point Likert scale with values ranging from 'strongly disagree' to 'strongly agree'.

EC Advantages. EC advantages were measured by 32 items distributed as follow: three items for the growth variable; ten items for the cost reduction variable; six items for the productivity variable; six items for the variable quality improvement variable; and seven for the strategic advantage variable. Each item was assessed using a five Likert scale with values ranging from 'strong decrease' to 'strong increase'.

\subsection{Data collection}

Data were collected by the means of a mailed questionnaire. The questionnaire was first pre-tested, resulting in minor changes. The final version of the questionnaire was then mailed to 1000 Canadian organisations engaged in EC. Two weeks after the mailing of the questionnaire, a recall letter was sent. A second recall letter was mailed a month after the initial mailing.

The current study targeted organisations randomly selected from "The Blue Book of Canadian Business" online database. The questionnaire was sent to the top manager in charge EC activities. One hundred and eighty six completed questionnaires were received. Forty three questionnaires were invalidated due to missing data or the organisation not being involved into EC, for a final sample of 143 organisations and a response rate of $14.3 \%$. Phone calls were made and emails sent to a number of non-respondent organisations in order to understand the reasons for not participating in the survey. The reasons fell into three categories:

- the respondent is too busy

- the questionnaire did not apply to the organisation

- wrong mailing address.

Sampled organisations were from various sectors. However we noted a predominance of manufacturing companies (17\%), banks and other financial services $(13 \%)$, transportation and distribution (11\%), and IS consulting companies (9\%). More than 50\% of organisations had less than a 1000 employees. Twenty eight percent had between 1000 and 10,000 employees, while 13\% had more than 10,000 employees. Most of the respondent organisations (almost 60\%) have been using EC for a duration ranging from one to three years.

As shown in Table 1, EC applications in use integrated various business functions and processes. However, a high proportion of these organisations were using their EC applications as a communication tool $(66 \%)$ or as a sales/marketing medium $(63 \%)$. More than two-third of the participants had integrated the ordering process to their EC applications, compared to $31 \%$ and $38 \%$ that had respectively incorporated their 
purchasing and customers' management activities to their applications. Finally, 22\% of the organisations were performing electronic payment through EC.

Table 1 Business functions and processes integrated within EC

\begin{tabular}{lcc}
\hline Business Functions/Processes & Frequency $^{a}(n=143)$ & Percentage $^{-143}$ \\
\hline Online order entry and tracking & 97 & 67.8 \\
Communication & 95 & 66.4 \\
Sales/Marketing & 90 & 62.9 \\
Customer management & 54 & 37.8 \\
Products/Services purchasing & 45 & 31.5 \\
Delivery & 34 & 23.8 \\
Billing & 33 & 23.1 \\
Electronic payment & 32 & 22.4 \\
Accounting & 29 & 20.3 \\
Product/Service design & 28 & 19.6 \\
Supplier management & 20 & 14.0 \\
Human resources management & 18 & 12.6 \\
Transportation/Distribution) & 17 & 11.9 \\
Inventory & 16 & 11.2 \\
Quality control & 12 & 8.4 \\
Payroll & 12 & 8.4 \\
Materials management & 11 & 7.7 \\
Production & 7 & 4.9 \\
Other & 15 & 10.5 \\
\hline
\end{tabular}

${ }^{\mathrm{a}}$ Certain organisations have integrated more than one function/process through EC.

Online ordering, communication, and sales/marketing are the most integrated businesses processes/functions into EC applications for the following reason. As noted above, a large proportion of the companies surveyed in this study (41\%) belong to the manufacturing, transportation and distribution sectors. Usually, companies in these sectors are involved in high volumes of transactions and communications with their customers and suppliers during pre-sales, sales, and post-sales activities. EC applications include functionalities (i.e.,: discussion forums, shopping cart, chat rooms, etc.) that make them suitable in supporting both direct sales, marketing as well as interactive communications. This may explain why online order (direct sales), communication, and sales/marketing are mostly integrated to EC applications in the current study.

\section{Results}

Structural equation modelling was used to assess the research model. The Partial-LeastSquares (PLS) method was chosen for its robustness, as it does not require a large sample or normally distributed multivariate data in comparison with covariance-based methods such as LISREL and EQS (Fornell and Bookstein, 1982). Note that in contrast to these 
methods, PLS does not provide overall model fit indices such as the likelihood-ratio chi-square $\left(\chi^{2}\right)$, the Goodness of Fit Index (GFI) or the Root Mean Residual (RMR). In this case, good model fit is determined by significant path coefficients ( $t$ values calculated with a bootstrap or jackknife method), sufficiently high explained variance $\left(R^{2}\right)$, and internal consistency (reliability coefficient above 0.70 for each construct) (Gefen et al., 2000).

As recommended by Anderson and Gerbing (1988), the data were analysed in two steps. First, the validity of the research constructs was assessed from a separate estimation and re-specification of the measurement model by confirmatory factor analyses. Second, the research model was tested by the simultaneous estimation of the measurement and theoretical (or structural) models.

\subsection{Assessment of construct validity}

The PLS method was first used to assess the construct validity of the six constructs included in the research model. Using the data from the 143 organisations sampled, estimates of the measurement model's parameters such as factor loadings and correlations were obtained. The primary aim here is to confirm the unidimensionality, reliability, convergent validity and discriminant validity of the constructs' dimensions so that each of these dimensions can be treated as a single value when testing the research model.

Advantages. A first-order Confirmatory Factor Analysis (CFA) of the Advantages construct was conducted, aiming to validate a posteriori the hypothesised dimensional structure of this construct, that is, the growth, cost reduction, productivity, quality and competitive advantage dimensions. Unidimensionality was assessed by examining the strength of the loadings. As shown in Figure 2, one item (out of 32) did not load sufficiently on its associated dimension (quality) and was thus deleted from the measurement model in order to preserve unidimensionality as a necessary condition to assign meaning to the estimated dimension (Anderson and Gerbing, 1988). Reliability was assessed with the $\rho$ coefficient, that is, the ratio of construct variance to the sum of construct and error variance, as follows: $\rho=\left(\Sigma\left|\lambda_{i}\right|\right)^{2} /\left(\Sigma\left|\lambda_{i}\right|\right)^{2}+\Sigma\left(1-\lambda_{i}^{2}\right)$ where $\lambda_{i}$ is the standardised loading relating measurement item $i$ to the dimension. Similarly to Cronbach's $\alpha$ coefficient, $\rho$ can be interpreted as acceptable when it is greater than 0.70 , indicating that at least $70 \%$ of the variance in measurement is captured by the construct variance (Fornell and Larcker, 1981). Returning to Figure 2, the 0.85-0.92 range obtained for the $\rho$ values thus confirms the internal consistency of the five dimensions of the Advantages construct.

Convergent validity is confirmed by looking at the Average Variance Extracted $\left(\mathrm{AVE}=\sum \lambda_{i}^{2} / n\right)$, i.e., the proportion of variance not due to measurement error (Fornell and Larcker, 1981). Here, as shown in Figure 2, AVE values equal or greater than 0.5 for all five dimensions support their convergent validity (Gerbing and Anderson, 1988). Discriminant validity shows the extent to which each dimension is unique and different from the others. The shared variance between a dimension and other dimensions of the construct (i.e., the squared correlation between two dimensions) must be less than the average variance extracted by a dimension from its measures (Fornell and Larcker, 1981). The correlations and AVE values presented in Figure 2 show this to be the case for all five dimensions of the Advantages construct. 
Figure 2 Confirmatory factor analysis of the EC advantages construct

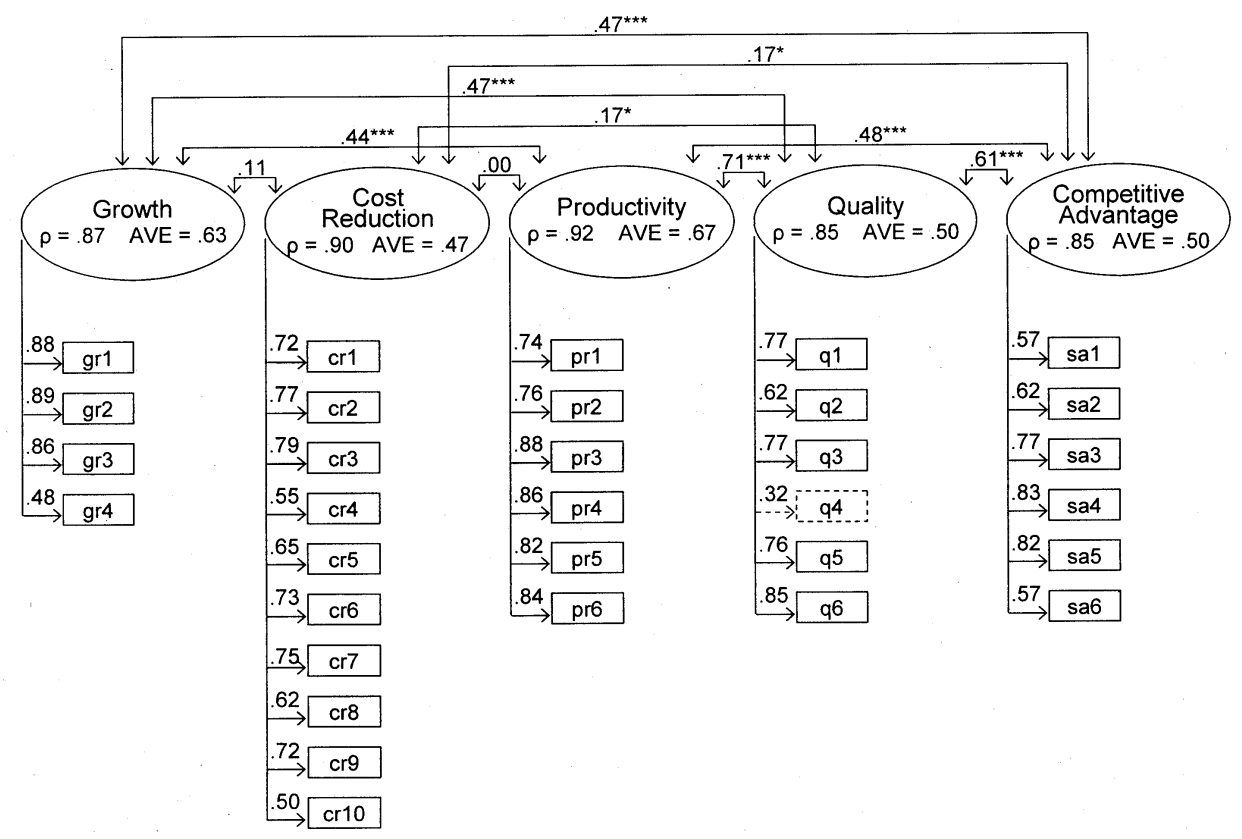

Type of Use. A first-order CFA was similarly conducted for the Type of use construct. As shown in Figure 3, two items (out of 27) did not load sufficiently on their associated dimension (informational use) and were thus deleted from the measurement model to preserve unidimensionality. Values for the $\rho$ coefficients $(0.83-0.89)$ and average variance extracted $(0.44-0.60)$ on each dimension, and for the correlations between dimensions (0.40-0.67) provide sufficient evidence of construct validity in terms of reliability, convergent validity and discriminant validity respectively.

Strategic Orientation. The CFA results presented in Figure 4 show that two items (out of 19) did not load sufficiently on their respective dimensions (cost and differentiation). After deletion of these items, $\rho$ (0.78-0.86), AVE (0.45-0.55) and correlation (0.24-0.41) values provide adequate confirmation of reliability, convergent validity and discriminant validity.

Organisational Context. The CFA results presented in Figure 5 show that one item (out of 20) did not load sufficiently on the organisational support dimension. After removal of this item from the measurement model, the reliability, convergent validity and discriminant validity of the two dimensions are shown to be adequate.

Integration and Level of Use. As presented in Figure 6, the two dimensions of the Integration construct are both measured with a single item, thus insuring unidimensionality, reliability, and convergent validity. Discriminant validity is confirmed by level of correlation (0.31) between internal and external integration. As the Level of Use construct presented in Figure 7 was defined subjectively in terms of a single dimension, namely internalisation, unidimensionality is confirmed by item 
loadings in the $0.61-0.79$ range. Reliability $(\rho=0.86)$ and convergent validity $(\mathrm{AVE}=0.51)$ are also confirmed, whereas discriminant validity does not apply.

Figure 3 Confirmatory factor analysis of the type of use construct

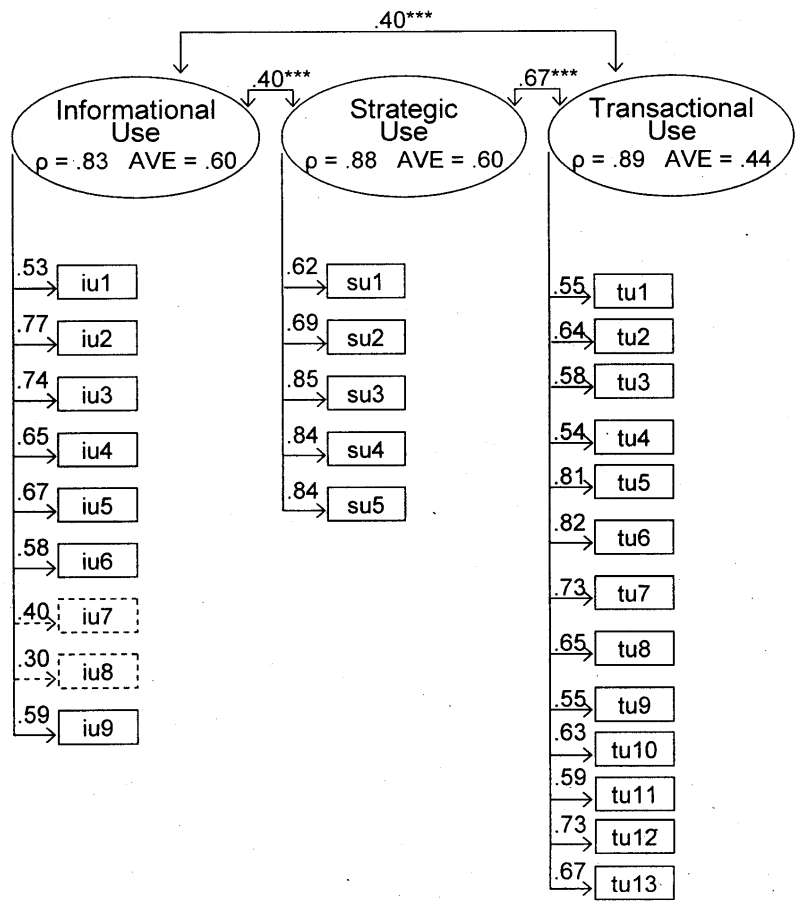

${ }^{*}: p<0.05^{* *}: p<0.01^{* * *}: p<0.001$

Figure 4 Confirmatory factor analysis of the strategic orientation construct

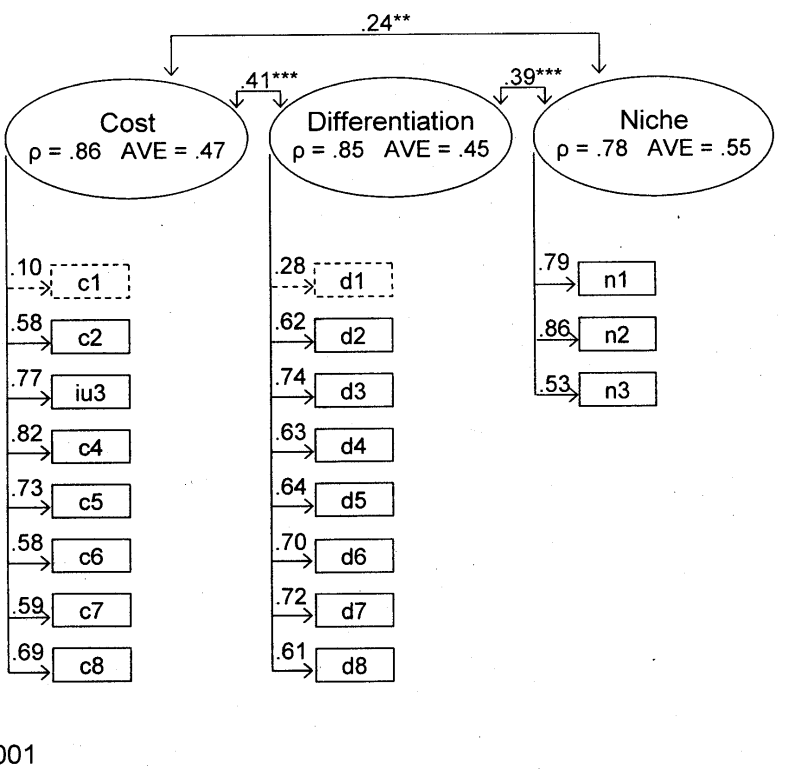


Figure 5 Confirmatory factor analysis of the organisational context construct

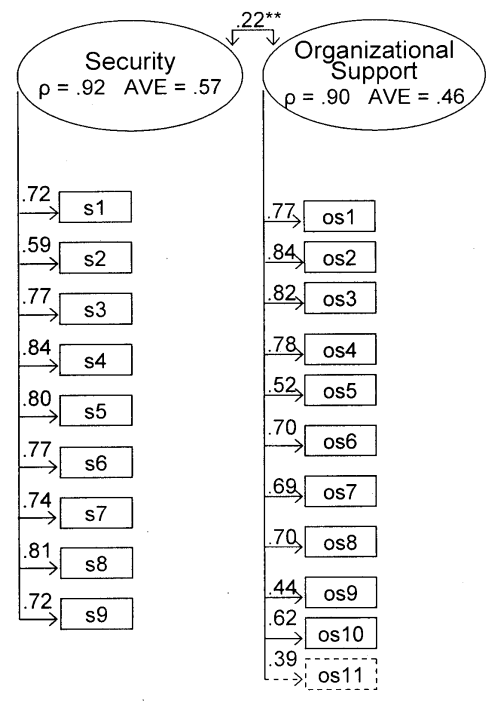

$\star *: p<0.01$

Figure 6 Confirmatory factor analysis of the integration construct

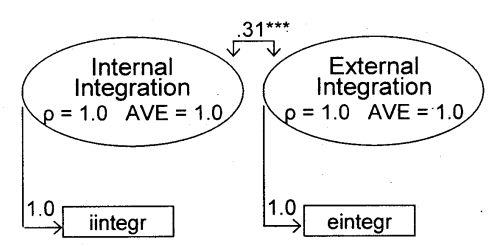

$\star \star *: p<0.001$

Figure 7 Confirmatory factor analysis of the level of use construct

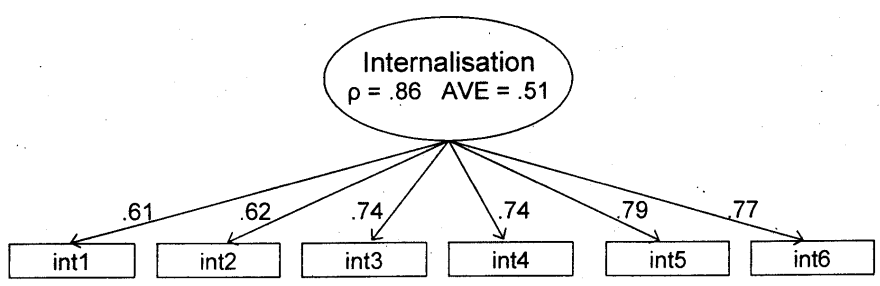

\subsection{Assessment of the measurement model}

The second step in the data analysis consists in simultaneously estimating with PLS the measurement and theoretical models. The unidimensionality and reliability of the research constructs must first be evaluated. As shown in Figure 8, whereas all loadings were adequate for five out of the six constructs, a loading equal to 0.22 for the cost reduction dimension of the EC advantages construct. This implies that in their final measurement, the advantages obtained from EC entails growth, productivity, quality, and competitive advantage but minimal reduction in costs. Hence, further results of testing 
the research model must be interpreted with this meaning of the EC advantages construct in mind. The $\rho$ coefficient values presented in Table 2 , ranging from $0.77-1$, then provide evidence of the six constructs' reliability.

There is also evidence in Table 2 of the convergent validity of the constructs, as their AVE ranges from $0.68-1$ in value. Finally, discriminant validity is confirmed as the correlation and AVE values presented in Table 2 indicate that the shared variance between any of the six constructs and the other five constructs is less than the average variance that it extracts from its measures.

Figure 8 Test of the research model with PLS $(n=143)$

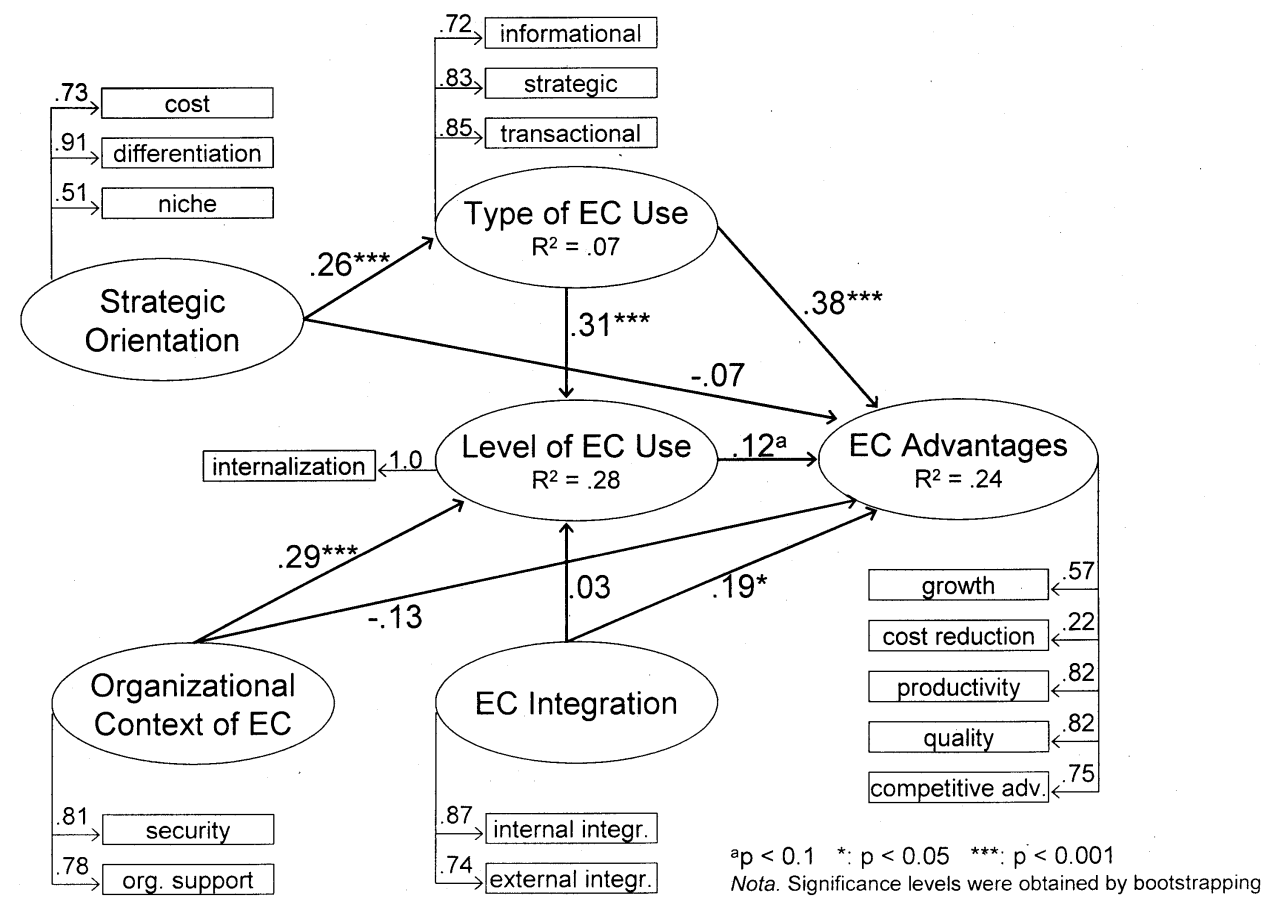

Table 2 Reliability, convergent and discriminant validity of the research constructs

\begin{tabular}{lccccccc}
\hline & $\rho^{a}$ & 1 & 2 & 3 & 4 & 5 & 6 \\
\hline Strategic orientation & 0.77 & $0.74^{\mathrm{b}}$ & & & & & \\
Type of use & 0.84 & 0.26 & 0.80 & & & & \\
Level of use & 1.0 & 0.26 & 0.47 & 1.0 & & & \\
Advantages & 0.79 & 0.06 & 0.44 & 0.28 & 0.8 & & \\
Organisational context & 0.78 & 0.29 & 0.49 & 0.45 & 0.17 & 0.80 & \\
Integration & 0.79 & 0.22 & 0.44 & 0.29 & 0.33 & 0.41 & 0.81 \\
\hline
\end{tabular}

${ }^{\mathrm{a}}$ Fornell and Larcker's coefficient of construct

$$
\text { reliability }=\left(\sum \lambda_{i}\right)^{2} /\left(\left(\sum \lambda_{i}\right)^{2}+\sum\left(1-\lambda_{i}^{2}\right)\right)
$$

bdiagonal: $\quad(\text { average variance extracted })^{1 / 2}=\left(\sum \lambda_{i}^{2} / n\right)^{1 / 2}$.

sub-diagonals: correlation $=(\text { shared variance })^{1 / 2}$. 


\subsection{Assessment of the theoretical model}

The research hypotheses are tested by assessing the direction, strength and level of significance of the path coefficients estimated by PLS, as shown in Figure 8. Descriptive statistics and correlations of the research variables are found in Appendices A and B.

Relationship between Level of Use and Advantages (H1). A positive path coefficient $\left(\gamma_{1}=0.12, p<0.1\right)$ indicates that a higher level of use of EC is associated with greater advantages obtained from EC in terms of growth, productivity, quality and competitive advantage. Hence Hypothesis 1 is only partly confirmed. The relative weakness of this relationship, notwithstanding its significance, also means that there are no significant indirect effects on Advantages, through Level of Use, from Type of Use $(0.12 \times 0.31=0.037)$, Organisational Context $(0.12 \times 0.29=0.035)$ and Integration $(0.12 \times 0.03=0.004)$.

Relationship between Strategic Orientation and EC Advantages (H2). As indicated by a path coefficient $\left(\gamma_{2}\right)$ equal to -0.07 (non significant), there is no direct effect of Strategic Orientation upon the attainment of Advantages from EC. The second hypothesis thus cannot be confirmed. Strategic Orientation is however seen to affect Advantages somewhat indirectly, through its influence on the Type of Use that is made of EC $(0.26 \times 0.38=0.099)$.

Relationship between Strategic Orientation and Type of EC Use (H3). A direct effect $\left(\gamma_{3}\right)$ is demonstrated by a highly significant path coefficient that links Strategic Orientation to Type of Use $(0.26, p<0.001)$, confirming Hypothesis 3 . This result highlights the fundamental relationship between the firm's competitive strategy and the purposes for which it uses EC, be they informational, strategic or transactional.

Relationship between Type of EC Use and EC Advantages (H4). A significant path coefficient linking Type of Use and Advantages $(0.38, p<0.001)$ confirms the presence of a direct effect $\left(\gamma_{4}\right)$ as posited. This result would highlight the fact that in conjunction with the firm's strategic aims, it is the purposes for which EC are used rather than the extent to which they are used that determine the creation of value for the firm, its customers, and its business partners.

Relationship between Type of EC Use and Level of EC Use (H5). A significant path coefficient $\left(\gamma_{5}=0.31, p<0.001\right)$ confirms that increased informational, strategic and transactional use of EC is associated with systems that are used in more depth by the firm, that is, that are more internalised in its business processes. This also implies that 'breadth' and 'depth' of use should be examined in conjunction when investigating the assimilation or infusion of EC in organisations.

Relationship between Organisational Context and Level of EC Use (H6). A significant path coefficient linking Organisational Context to Advantages $\left(\gamma_{6}=0.29, p<0.001\right)$ confirms the sixth research hypothesis. Given the results of previous studies on IT adoption and assimilation, this result would again highlight the fact that adequate levels of IT support and IT security provided by the firm are co-requisites to its greater assimilation of EC.

Relationship between Organisational Context and EC Advantages (H7). A negative and non significant path coefficient linking Organisational Context and Advantages 
$\left(\gamma_{7}=-0.13\right)$ means that Hypothesis 7 cannot be confirmed. Thus, as is the case for the firm's strategic orientation, its organisational context for EC directly affects its behaviour in terms of systems use but not the consequences of this behaviour in terms of performance gains.

Relationship between EC Integration and Level of EC Use (H8). The eight hypothesis could not be confirmed as the path coefficient linking Integration to Level of Use is non significant $\left(\gamma_{8}=0.03\right)$. One can note however a strong association between internal integration and the transactional use of the internet, as indicated by a correlation value of 0.55 between these two variables (see Appendix B). A firm that is highly integrated internally, say through an Enterprise Resource Planning (ERP) system, could be in better position to implement transactional EC, say through 'extended' ERP. Integration could thus directly affect Type of Use more than it affects Level of Use.

Relationship between EC Integration and EC Advantages (H9). A significant path coefficient linking Integration to Advantages $\left(\gamma_{9}=0.19, p<0.05\right)$ confirms Hypothesis 9 . Firms that exhibit higher levels of internal and external integration are seen to obtain more value from their use of EC, be it in terms of growth, productivity increases, better quality, or the attainment of a competitive advantage.

Overall, the research model explains a significant part (24\%) of the variance in the advantages obtained by the sampled firms from EC, mostly due to the direct effect of the type of use and level of integration of these systems. Whereas a significant proportion of variance in the level of use (28\%) is explained by the sampled firms' type of use of EC, be it for informational, strategic, or transactional purposes and by their organisational context in terms of support and security provided for EC.

\section{Discussion}

EC has been studied under different perspectives and is generally believed to bring positive impacts on firms. However, not much is known about the exact advantages of EC and the conditions under which such advantages can be obtained. This research shed some light on these important questions.

Research results indicate that firms obtain various advantages from EC activities. The most important advantages are increases in productivity, quality of products and services, competitive advantage, and to a lesser extent, in sales growth and revenues. Cost reductions were only marginal. The limited contribution of EC to cost reductions may be due to the cost of IT infrastructure that would wipe off other economies in other parts of the business value chain. It is also possible that cost reduction can be observed only in the long run or else when EC has been implemented for a sufficient length of time. Also, the IT investments are possibly needed to obtain the other advantages and they might simply represent the cost of doing business.

$\mathrm{EC}$ advantages can be explained by various factors. To ease the discussion of results, the direct effects of the predictors on EC advantages will be discussed first, followed by the indirect effects. The factors having a direct effect on EC advantages are the type of EC use, the integration of EC applications, and to a lesser extent, the level of use (internalisation). The most important direct effect is the type of use. It indicates that the firm must choose a predominant orientation for its website which can be transactional, 
strategic or informational. The data do not allow to link specific advantages to specific type of use but one could surmise that transactional sites could be associated with higher productivity, informational sites associated better quality of products and services, and a strategic site related to sustainer or renewed competitive advantage. The integration of applications is the second factor influencing the EC advantages. It is possible that the internal integration of applications within the firm brings a higher productivity, and a better quality of product and services, while external integration with business partners (clients, suppliers, distributors) is more related to improvements in growth and competitive advantages. As a third factor, the contribution of the level of use (or internalisation) to the advantages is present but somewhat limited. This might be due to a deficient measure of the concept, a lack of variability of the measure, or simply that type of use and integration are the most important predictors.

In terms of indirect effects on the advantages, it can be observed that the strategic orientation of the firm has a direct effect on the type of use which in turn has a direct effect on the advantages. But there is no direct effect of strategic orientation on advantages, only an indirect one. This indicates that a specific strategic orientation, per se, is not a pre-requisite to the attainment of EC advantages, but it will help to have the strategic orientation and the type of use fit together. Any strategic orientation can be appropriate but it is only if the type of EC use is aligned with the strategic orientation of the firm that advantages can be obtained.

The organisational context, defined in terms of organisational support and security, does not have a direct effect on the advantages either but it directly influences the level of use which in turn is related to advantages. In fact, the type of use is also important in the determination of the level of use and it is the combination of the type of use and the organisational context that influences, but lightly, the level of use.

Altogether, the type of EC use, the internal and external integration, and the level of use play a direct role in explaining variations in EC advantages, while the strategic orientation of the firm and the organisational context exert only an indirect effect and as such can be considered as antecedent conditions to EC advantages.

\section{Limitations}

There are some limitations to this research. First, this is a survey research and we have not been able to collect data on non-respondents who could have a different opinion of the participants to the survey. The data are also subjective since they collect the respondents' opinions and these are not objective data. The use of a questionnaire can also carry the threat of a common method variance. Second, there is a possibility of a longer delay than the one that is taken into account between the time the investments are made in EC and the actual realisation of advantages. Third, a limitation of this study relates to the choice of PLS as the statistical method, imposed by the size of the sample, over covariance structure analysis approaches such as LISREL and EQS. PLS, was appropriate in this theory building research but it is more prone to accept hypotheses than other theory testing methods. The PLS technique is more suitable for predictive applications than for theory testing (Anderson and Gerbing, 1988) and tends to underestimate structural paths when compared with LISREL or EQS (Chin, 1995). A more strict structural equations statistical technique might have concluded in fewer demonstrated relationships among variables. 
The results and implications of this study must be considered in light of the intrinsic limitations of survey research. The nature and relatively small size of the sample limit the capacity to generalise research findings across all types of business organisations. The cross-sectional, as opposed to longitudinal nature of the research design, implies that true causal relationships between the research constructs cannot be inferred. Also, while these constructs were shown to be valid, there may yet be survey biases related to the subjective nature of the data. Relying on the perceptions of one key informant may also imply cognitive biases.

\section{Conclusion}

EC has brought major changes in the way organisations conduct their business activities. However, there have been relatively few empirical studies that aimed to explain what kind of benefits they can expect from the implementation and use of EC applications, as well as the conditions under which businesses can optimise these benefits. In light of this, the purpose of this study was to investigate the actual advantages of EC and determinants of these advantages. A research model including potential advantages and factors explaining these advantages was designed and empirically tested within a sample of 1000 companies.

Key findings indicate that the most important advantages of EC are increased productivity, increased quality of products and services, competitive advantage, and to a lesser extent, sales growth and increased revenues. Cost reductions were marginal. According to the results of this study, there are two categories of determinants of EC advantages. The first category comprises factors that have a direct effect on EC advantages. These include the type of EC use (with the most important direct effect); the internal and external integrations of EC applications; and to a lesser extent, the level of use (internalisation) of EC. Factors such the strategic orientation of the firm and the organisational context exert an indirect effect on EC advantages. The strategic orientation has a direct effect on the type of use which in turn has a direct effect on the advantages. The organisational context, defined in terms of organisational support and security, directly influences the level of EC use which in turn is related to advantages.

The main academic contribution for this study resides in the fact that it provides an integrative model that have been empirically tested and that helps to better understand EC advantages and key factors that determine these advantages. The tested model integrate constructs from IS and strategic management field. Managers can also benefit from the current study. This research has empirically demonstrated that organisations can gain various benefits from EC. The most important ones are increased productivity, increased quality of products and services, competitive advantage, sales growth and increased revenues. However, this study does not show huge costs reductions. These are marginal. One can imagine that costs reductions can be observed in the long term. In the short term however, competitive pressure may force organisations to invest in EC in order to survive. Among the factors that explain EC advantages, managers must pay close attention to the type of use and the integration of EC applications. In order to benefit the most from EC, the organisation should design, implement and use its EC applications in a way that support adequately its strategic orientation. There is no recommendation on which specific type of EC use (informational, transaction and/or strategic) should lead to more advantages. Each type of use has its own advantages and it will appropriate only if 
it supports the organisation's competitive strategy. In addition to what precedes, organisations should make sure that EC applications are integrated with existing internal systems and business partners (customers, suppliers, distributors, banks, government agencies, etc.) in order to profit the most from EC.

While this study brings some insights on EC advantages and some factors explaining these advantages, there is still much work to do relative to the technological, organisational and environmental context into which EC can flourish. The impact of EC on the organisation would also gain to be studied under the human and national perspectives in addition to financial and operational effectiveness. Future research will take this into account.

\section{References}

Amit, R. and Zott, C. (2001) 'Value creation in e-business', Strategic Management Journal, Vol. 22, Nos. 6-7, pp.493-520.

Anderson, J.C. and Gerbing, D.W. (1988) 'Structural equation modeling in practice: a review and recommended two-step procedure', Psychological Bulletin, Vol. 103, No. 3, pp.411-423.

Applegate, L.M., Holsapple, C.W., Kalakota, R., Radermacher, F. and Whinston, A.B. (1996) 'Editorial: electronic commerce: building blocks of new business opportunity', Journal of Organizational Computing and Electronic Commerce, Vol. 6, No. 1, pp.1-10.

Avlonitis, J.G. and Karayanni, D.A. (1996) 'The Use of internet in business-to-business marketing: some evidence from American and European Companies', Work-in-Progess Paper, http://lyttos.aueb.gr/karayanni.

Bakos, J.Y. (1991) 'A strategic analysis of electronic marketplaces', MIS Quarterly, Vol. 15, No. 3, pp.295-310.

Banerjee, S. and Golhar, D.Y. (1994) 'Electronic data interchange: characteristics of user and nonusers', Information and Management, Vol. 26, No. 2, pp.65-74.

Bensaou, M., DeGross, J.I., Bostrom, R.P. and Robey, D. (Eds.) (1993) 'Interorganizational cooperation: the role of information technology, an empirical comparison of US and Japanese supplier relations', Proceedings of the Fourteenth International Conference on Information Systems, Orlando, pp.117-127.

Bergeron, F. and Raymond, L. (1997) 'Managing EDI for corporate advantage: a longitudinal study', Information and Management, Vol. 31, No. 6, pp.319-333.

Bergeron, F., Raymond, L., Rivard, S. and Gara, M.F. (1995) 'Determinants of EIS use: testing a behavioral model', Decision Support Systems, Vol. 14, No. 2, pp.131-146.

Bloch, M., Pigneur, Y. and Segev, A. (1996) On the Road of Electronic Commerce - a Business Value Framework, Ganing competitive Advantage and Some Research issues, http://pobox.com/ mb/docs/roadtoec/ec.htm.

Boyer, K.K. and Olson, R.J. (2004) 'Operations strategy and internet purchasing: a contingent model', International Journal of Electronic Business, Vol. 2, No. 1, pp.41-63.

Buzzel, R.D. and Gale, B.T. (1987) The PIMS Principles: Linking Strategy to Performance, Free Press, New York.

Chang, K., Jackson, J. and Grover, V. (2003) 'E-commerce and corporate strategy: an executive perspective', Information and Management, Vol. 40, No. 7, pp.663-675.

Chatfield, A.T. and Yetton, P. (2000) 'Strategic payoff from EDI as a function of EDI embeddedness', Journal of Management Information Systems, Vol. 16, No. 4, pp.195-224.

Chin, W.W. (1995) 'Partial least squares is to LISREL as principal components analysis is to common factor analysis', Technology Studies, Vol. 2, No. 2, pp.315-319. 
Chircu, A.M. and Kauffman, R.J. (2000) 'Limits to value in electronic commerce-related IT investments', Journal of Management Information Systems, Vol. 17, No. 2, pp.59-80.

Claycomb, C., Iyer, K. and Germain, R. (2005) 'Predicting the level of B2B e-commerce in industrial organizations', Industrial Marketing Management, Vol. 34, No. 3, pp.221-234.

DeLone, W.H. and McLean, E.R. (1992) 'Information systems success: the quest for the dependent variable', Information Systems Research, Vol. 3, No. 1, pp.60-95.

Devaraj, S. and Kohli, R. (2003) 'Performance impacts of information technology: Is actual usage the missing link?', Management Science, Vol. 49, No. 3, pp.273-289.

Elia, E., Lefebvre, L.A. and Lefebvre, E. (2007) 'Focus of B-to-B e-commerce initiatives and related benefits in manufacturing small - and medium-sized enterprises', Information Systems and eBusiness Management, Vol. 5, No. 1, pp.1-23.

Fornell, C.R. and Bookstein, F.L. (1982) 'Two structural equation models: LISREL and PLS applied to consumer exit-voice theory', Journal of Marketing Research, Vol. 19, No. 4, pp.440-452.

Fornell, C.R. and Larcker, D.F. (1981) 'Evaluating structural equation models with unobservable variables and measurement error', Journal of Marketing Research, Vol. 18, No. 1, pp.39-50.

Frohlich, M.T. and Westbrook, R. (2002) 'Demand chain management in manufacturing and services: web-based integration, drivers and performance', Journal of Operations Management, Vol. 20, No. 6, pp.729-745.

Fruhling, A.L. and Digman, L.A. (2000) 'The impact of electronic commerce on business-level strategies', Journal of Electronic Commerce Research, Vol. 1, No. 1, pp.13-22.

Gefen, D., Straub, D.W. and Boudreau, M-C. (2000) 'Structural equation modeling and regression: guidelines for research practice', Communications of the AIS, Vol. 4, No. 7, pp.1-76.

Gerbing, D.W. and Anderson, J.C. (1988) 'An updated paradigm for scale development incorporating unidimensionality and its assessment', Journal of Marketing Research, Vol. 25, No. 2, pp.186-192.

Grover, V. (1993) 'An empirically derived model for the adoption of customer-based interorganizational systems', Decision Sciences, Vol. 24, No. 3, pp.603-640.

Johnston, H.R. and Vitale, M.R. (1988) 'Creating competitive advantage with interorganizational information systems', MIS Quarterly, Vol. 12, No. 2, p.165.

Kauffman, R.J. and Walden, E. (2001) 'Economics and electronic commerce: survey and directions for research', International Journal of Electronic Commerce, Vol. 5, No. 4, Summer, pp.5-116.

Koh, C.E. and Balthazard, P. (1998) 'The action-audience model: a framework for internet-based electronic commerce and a survey of business internet use', Proceedings of the 29th Annual Meeting of the Decision Sciences Institute, Las Vegas, Nevada.

Koo, C.M., Koh, C.E. and Nam, K.C. (2004) 'An examination of Porter's competitive strategies in virtual electronic markets: comparison of two online business models', International Journal of Electronic Commerce, Vol. 9, No. 1, Fall, pp.163-180.

Kraemer, K.L., Gibbs, J. and Dedrick, J. (2005) 'Impacts of globalization on e-commerce use and firm performance: a cross-country investigation', The Information Society, Vol. 21, No. 5, pp.323-340.

Liao, Z. and Cheung, M.T. (2002) Internet-based e-banking and consumer attitudes: an empirical study', Information and Management, Vol. 39, No. 4, pp.283-295.

Margherio, L., Henry, D., Cooke S. and Montes, S. (1998) The Emerging Digital Economy, http://www.ecommercecommission.org/document/EmergingDig.pdf

Mata, F.J., Fuerst, W.L. and Barney, J.B. (1995) 'Information Technology and sustained competitive advantage: a resource-based analysis', MIS Quarterly, Vol. 19, No. 4, pp.487-505. 
McKeen, J.D. and Smith, H.A. (1993) 'The relationship between information technology use and organizational performance', in Banker, R.D., Kauffman, R.J and Mahmood, M.A. (Eds.): Strategic Information Technology Management: Perspectives on Organizational Growth and Competitive Advantage, Idea Group Publishing, Hershey, PA, pp.405-444.

Melville, N., Kraemer, K. and Gurbaxani, V. (2004) 'Information technology and organizational performance: an integrative model of IT business value', MIS Quarterly, Vol. 28, No. 2, pp.283-322.

Merono-Cerdan, L.A. and Soto-Acosta, P. (2005) 'Examining e-business impact on firm performance through website analysis', International Journal of Electronic Business, Vol. 3, No. 6, pp.583-598.

Miller, A. (1988) 'Taxonomy of technological settings, with related strategies and performance levels', Strategic Management Journal, Vol. 9, No. 3, pp.239-254.

Mukhopadhyay, T. (1998) 'How to win with electronic data interchange', in Kemerer, C.F. (Ed.): Information Technology and Industrial Competitiveness: How IT Shapes Competition, Kluver Academic, Boston, pp.91-106.

Nambisan, S. and Wang, Y. (1999) 'Roadblocks to web technology adoption', Communications of the ACM, Vol. 42, No. 1, pp.98-101.

Neo, B.S., Khoo, P.E. and Ang, S. (1994) 'The adoption of tradenet by the trading community: an empirical analysis' in DeGross, J.I., Huff, S. and Munro, M.C. (Eds.): Proceedings of the Fifteenth International Conference on Information Systems, Vancouver, pp.159-174.

Ngai, E.W.T and Wat, F.K.T. (2002) 'A literature review and classification of electronic commerce research', Information and Management, Vol. 39, No. 5, pp.415-429.

Palvia, P.C. (1997) 'Developing a model of the global and strategic impact of information technology', Information and Management, Vol. 32, No. 5, pp.229-244.

Pflughoeft, K.A., Ramamurthy, K., Soofi, E.S., Yasai-Ardekani, M. and Zahedi F.M. (2003) 'Multiple conceptualizations of small business web use and benefit', Decision Sciences, Vol. 34, No. 3, Summer, pp.467-512.

Pires, G.D. and Aisbett, J. (2003) 'The relationship between technology adoption and strategy in business-to-business markets: the case of e-commerce', Industrial Marketing Management, Vol. 32, No. 4, pp.291-300.

Porter, M.E. (1980) Competitive Strategy: Techniques for Analyzing Industries and Competitors, Free Press, New York.

Porter, M.E. (2001) 'Strategy and the internet', Harvard Business Review, Vol. 79, No. 3, pp.63-78.

Ramamurthy, K. and Premkumar, G. (1995) 'Determinants and outcomes of EDI diffusion', IEEE Transactions on Engineering Management, Vol. 32, No. 4, pp.332-351.

Ranganathan, C., Dhaliwal, J.S. and Teo, T.S. (2004) 'Assimilation and diffusion of web technologies in supply-chain management: an examination of key drivers and performance impacts', International Journal of Electronic Commerce, Vol. 9, No. 1, Fall, pp.127-161.

Raymond, L. and Bergeron, F. (1996) 'EDI Success in small and medium-sized enterprises: a field study', Journal of Organizational Computing and Electronic Commerce, Vol. 6, No. 2, pp.161-172.

Raymond, L. and Bergeron, F. (1997) 'Global distribution systems: a field study of their use and advantages in travel agencies', Journal of Global Information Management, Vol. 5, No. 4, pp.23-32.

Riggins, F.J. and Rhee, H-S. (1998) 'Toward a unified view of electronic commerce', Communications of the ACM, Vol. 41, No. 10, pp.88-95.

Ross, J.W., Beath, C.M. and Goodhue, D.L. (1996) 'Develop long-term competitiveness through it assets', Sloan Management Review, Vol. 38, No. 1, pp.31-42. 
Sanders, N.R. (1992) 'Merging EDI with JIT: the impact on US manufacturing', Journal of Applied Business Research, Vol. 8, No. 2, pp.133-137.

Segev, E. (1989) 'A systematic comparative analysis and synthesis of two business-level strategic typologies', Strategic Management Journal, Vol. 10, No. 5, September-October, pp.487-505.

Seppanen, M. and Suomala, P. (2003) 'E-business in a B2B wholesaler's internal supply chain: effects on costs and activities', International Journal of Electronic Business, Vol. 1, No. 4, pp.347-357.

Sethi, V. and King, W.R. (1994) 'Development of measures to assess the extent to which an information technology application provides competitive advantage', Management Science, Vol. 40, No. 12, pp.1601-1627.

Shih, C.S. and Wen H.J. (2005) 'E-enterprise security management life cycle', Information Management and Computer Security, Vol. 13, No. 2, pp.121-134.

Shin, N. (2004) 'An empirical investigation of the economic payoffs of e-business and CRM Innovations', International Journal of Electronic Business, Vol. 2, No. 4, pp.351-365.

Strader, T.J. and Shaw, M.J. (1997) 'Characteristics of electronic markets', Decision Support Systems, Vol. 21, No. 3, pp.185-198.

Subramaniam, C. and Shaw, M.J. (2002) 'A study of the value and impact of B2B e-commerce: the case of web-based procurement', International Journal of Electronic Commerce, Vol. 6, No. 4, Summer, pp.19-40.

Suh, B. and Han, I. (2003) 'The impact of customer trust and perception of security control on the acceptance of electronic commerce', International Journal of Electronic Commerce, Vol. 7, No. 3, pp.135-161.

Swatman, P.M.C. and Swatman, P.A. (1991) 'Integrating EDI into the organization's systems: a model of the stages of integration', in DeGross, J.I., Benbasat, I., DeSanctis, G. and Mathis Beath, C. (Eds.): Proceedings of the 12th International Conference on Information Systems, New York, pp.141-153.

Tagliavini, M., Ravarini, A. and Antonelli (2001) 'An evaluation model for electronic commerce activities within SMEs', Information Technology and Management, Vol. 2, No. 2, pp.211-230.

Teo, H.H, Tan, B.C.Y., Wei, K.K. and Woo, L.Y. (1994) 'Leveraging EDIS to improve organizational and interorganizational productivity: findings from the world's busiest port', in DeGross, J.I., Huff, S. and Munro, M.C. (Eds.): Proceedings of the Fifteenth International Conference on Information Systems, Vancouver, pp.17-186.

Teo, T.SH. and Pian, Y. (2003) 'A contingency perspective on internet adoption and competitive advantage', European Journal of Information Systems, Vol. 12, No. 2, pp.78-92.

Teo, T.SH. and Too, B.L. (2000) 'Information systems orientation and business use of the internet: an empirical study', International Journal of Electronic Commerce, Vol. 4, No. 4, Summer, pp.105-130.

Teo, T.SH., Tan, M. and Wong, K.B. (1997-1998) 'A contingency model of internet adoption in Singapore', International Journal of Electronic Commerce, Vol. 2, No. 2, Winter, pp.95-118.

Teubner, W.R. (1998) 'Hosting the web: vitual private networks require web-to-host-gateway security', Electronic Commerce World, January, pp.28-31, http://www.ecomworld.com

Wade, M., Johnston, D. and McClean, R. (2004) 'Exploring the net impact of internet business solution adoption on SME performance', International Journal of Electronic Business, Vol. 2, No. 4, pp.336-350.

Wai-Pun, M.K., Farhoomand, A.F. and Tuunainen, V.K. (1997) 'A preliminary investigation of business opportunities on the internet in Asia Pacific', Proceedings, the 1st Pacific Asia Workshop on Electronic Commerce, 5th April, Queensland University of Technology, Brisbane. 
Weill, P. (1992) 'The relationship between investment in information technology and firm performance: a study of the valve manufacturing sector', Information Systems Research, Vol. 3, No. 4, pp.307-333.

Yao, Y., Palmer, J.W. and Dresner, M. (2002) 'Impacts of electronic commerce on supply chain management', in Applegate, L., Galliers, R. and DeGross, J. (Eds.): Proceedings of the Twenty-third International Conference on Information, Systems, Atlanta, pp.731-736.

Zaheer, A. and Venkatraman, N. (1994) 'Determinants of electronic integration in the insurance industry: an empirical test', Management Science, Vol. 40, No. 5, pp 549-566.

Zhu, K. (2004) 'The complementarity of information technology infrastructure and e-commerce capability: a resource-based assessment of their value', Journal of Management Information Systems, Vol. 21, No. 2, pp.167-202.

Zhu, K. and Kraemer L.K. (2005) 'Post-adoption variations in usage and value of e-business by organizations: cross-country evidence from the retail industry', Information Systems Research, Vol. 16, No. 1, pp.61-84.

Zhuang, Y., Lederer, L. and Childers L.T. (2006) 'Generic strategies for business-to-consumer e-commerce', International Journal of Electronic Business, Vol. 4, No. 6, pp.445-462.

\section{Appendix A: Descriptive statistics of the research variables}

\begin{tabular}{|c|c|c|c|c|c|}
\hline Construct variable & Mean & Median & S.d. & Min. & $\operatorname{Max}$ \\
\hline \multicolumn{6}{|l|}{ Strategic orientation } \\
\hline Cost & 4.0 & 4.0 & 0.6 & 2.1 & 5.0 \\
\hline Differentiation & 3.8 & 3.7 & 0.6 & 2.0 & 5.0 \\
\hline Niche & 3.9 & 4.0 & 0.7 & 2.0 & 5.0 \\
\hline \multicolumn{6}{|l|}{ Type of use } \\
\hline Informational use & 3.9 & 3.9 & 0.6 & 2.1 & 5.0 \\
\hline Strategic use & 2.9 & 3.0 & 0.9 & 1.0 & 5.0 \\
\hline Transactional use & 2.5 & 2.5 & 0.8 & 1.0 & 4.9 \\
\hline \multicolumn{6}{|l|}{ Level of use } \\
\hline Internalisation & 3.5 & 3.5 & 0.7 & 1.7 & 5.0 \\
\hline \multicolumn{6}{|l|}{ Advantages } \\
\hline Growth & 3.4 & 3.5 & 0.5 & 2.0 & 4.8 \\
\hline Cost reduction & 2.9 & 2.9 & 0.6 & 1.1 & 4.9 \\
\hline Productivity & 3.6 & 3.7 & 0.6 & 2.0 & 5.0 \\
\hline Quality & 3.5 & 3.6 & 0.5 & 2.0 & 4.8 \\
\hline Competitive advantage & 3.4 & 3.3 & 0.5 & 2.0 & 4.8 \\
\hline \multicolumn{6}{|l|}{ Organisational context } \\
\hline Security & 3.4 & 3.6 & 0.9 & 1.0 & 5.0 \\
\hline Organisational support & 3.7 & 3.8 & 0.7 & 1.9 & 5.0 \\
\hline \multicolumn{6}{|l|}{ Integration } \\
\hline Internal integration & 1.7 & 1.0 & 0.9 & 1.0 & 5.0 \\
\hline External integration & 2.3 & 2.0 & 0.8 & 1.0 & 5.0 \\
\hline
\end{tabular}




\section{Appendix B: Correlations of the research variables}

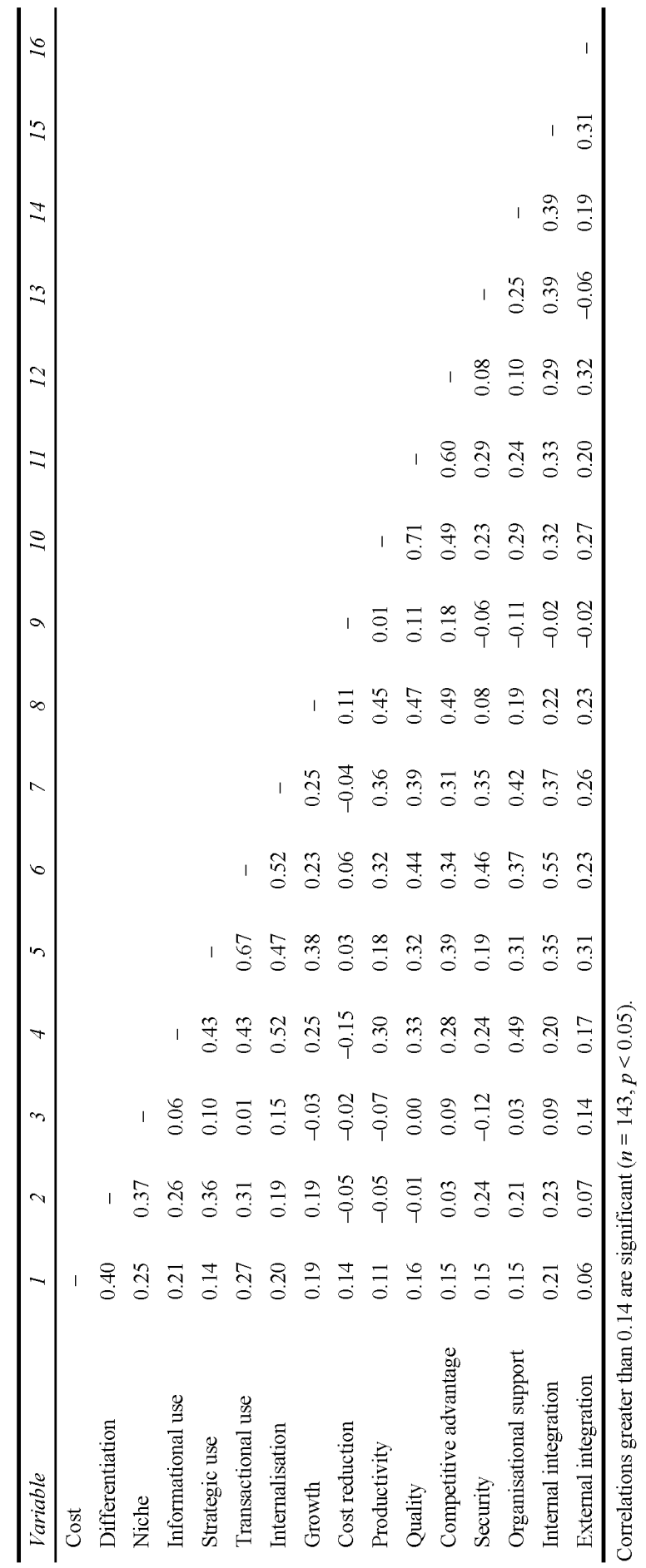




\section{Appendix C: Questionnaire}

\section{Part A: Strategic Orientation of the Organisation}

The questions below aim to determine the strategic orientation of your organisation ${ }^{1}$. Using the following scale, please, indicate the importance your organisation attaches to the following competitive activities. Please, circle the number that best represents your opinion.

$\begin{array}{llccc}\text { 1: } \begin{array}{l}\text { Not at all } \\ \text { important }\end{array} & \begin{array}{c}\text { 2: Slightly } \\ \text { important }\end{array} & \begin{array}{c}\text { 3: } \text { Moderately } \\ \text { Important }\end{array} & \begin{array}{c}\text { 4: Very } \\ \text { important }\end{array} & \begin{array}{r}\text { 5: Extremely } \\ \text { important }\end{array}\end{array}$

c1 Achieving lower cost of products/services than competitors

c2 Improving the time/cost required for coordination of various services

c3 Improving the utilisation of available equipment, services and facilities

c4 Increasing operating efficiency

c5 Improving staff productivity

c6 Facilitating the procurement of resources

c7 Increasing the efficiency of the distribution channels

c8 Reducing production costs

d1 Offering competitive prices

d2 Offering a broader range of products/services than the competitors

d3 Differentiating products/services from competitors

d4 Offering a higher level of service

d5 Introducing new products/services

d6 Innovating in marketing methods and techniques

d7 Offering superior guaranties on products/services

d8 Allowing brand recognition

n1 Tailoring products/services to special customer needs

n2 Offering specific products/services

n3 Serving specific geographical markets or specific market segments

sol Please indicate other possible aspects of your organisation's strategic orientation which do not appear among those enumerated above:

${ }^{1} \mathrm{c}=$ cost leadership

$\mathrm{d}=$ differentiation

$\mathrm{n}=$ niche

$\mathrm{so}=$ strategic orientation open question.

\section{Part B: Organisational Context of EC}

In this section, we would like to know the organisational context ${ }^{2}$ in which your Internet-based Electronic Commerce System (IECS) is implemented. Using the following scale, please indicate for each of the following statements, the extent to which they are representative of your IECS implementation process in your organisation. Please, circle the number that best represents your opinion. 


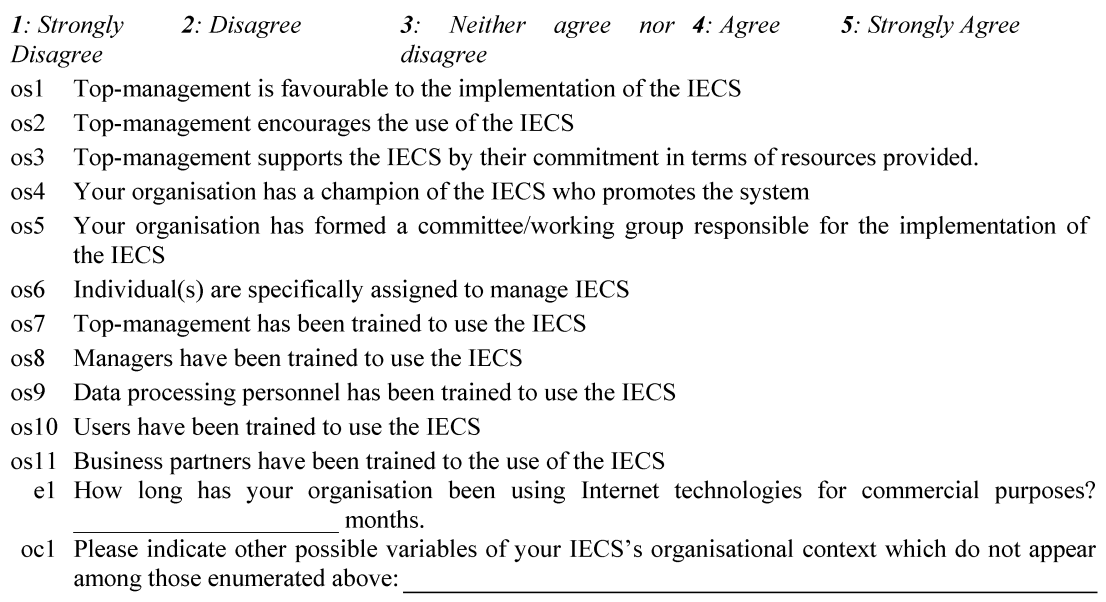

oc1 Please indicate other possible variables of your IECS's organisational context which do not appear among those enumerated above:

\section{Part C: Level of Security of EC}

In this section, we would like to know the level of security of your $\operatorname{IECS}^{3}$ Using the following scale, please indicate for each of the following statements, the extent to which they are representative of the level of security of your IECS. Please, circle the number that best represents your opinion.

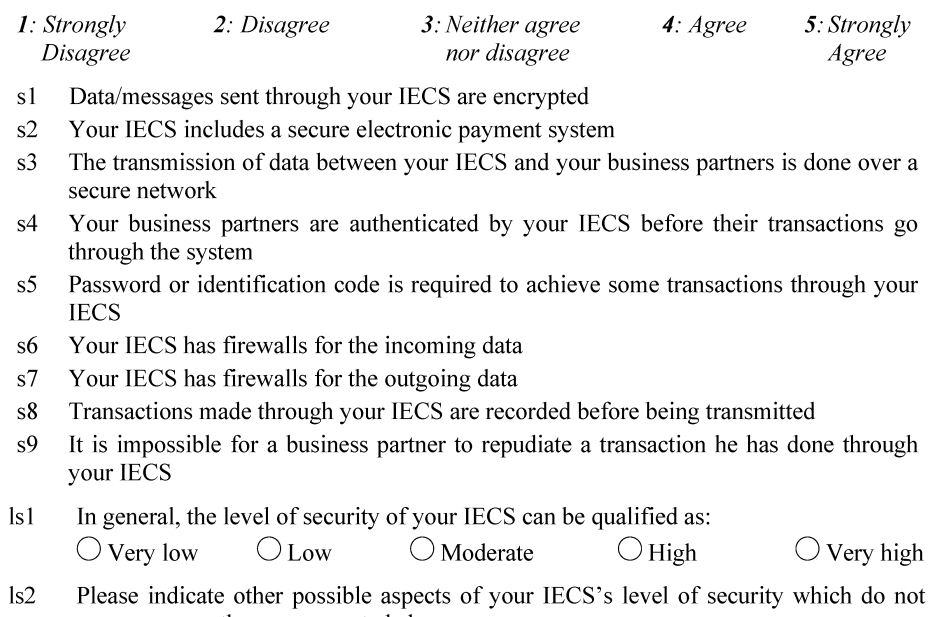
appear among those enumerated above:

${ }^{3} \mathrm{~s}=$ security

$\mathrm{e}=$ experience with Internet

ls = level of security open question. 


\section{Part D: Level of EC Integration}

In this section, we would like to know the number of administrative functions and the number of business partners linked to your IECS ${ }^{4}$.

iintegr Please check the different types of internal applications integrated to your IECS.

$\begin{array}{lll}\square \text { Purchasing } & \square \text { Billing } & \square \text { Wage system } \\ \square \begin{array}{l}\text { Ordering } \\ \text { Internal } \\ \text { communication }\end{array} & \square \text { Supplier management } & \square \text { Manufacturing } \\ \square \text { Accounting } & \square \text { Material resources } & \square \text { Online orders tracking } \\ \square \text { Conception/Design } & \square \text { Inventory management } & \square \text { Electronic Fund Transfer } \\ \square \text { Quality control } & \square \text { Personnel management } & \square \text { Transport (distribution) } \\ \square \text { Shipping/Delivery } & \square \text { Catalog maintenance } & \square \text { Sales/Marketing } \\ \square \text { Other (please specify) : }\end{array}$

eintegr Please, indicate the proportion of your business partners connected to your IECS :

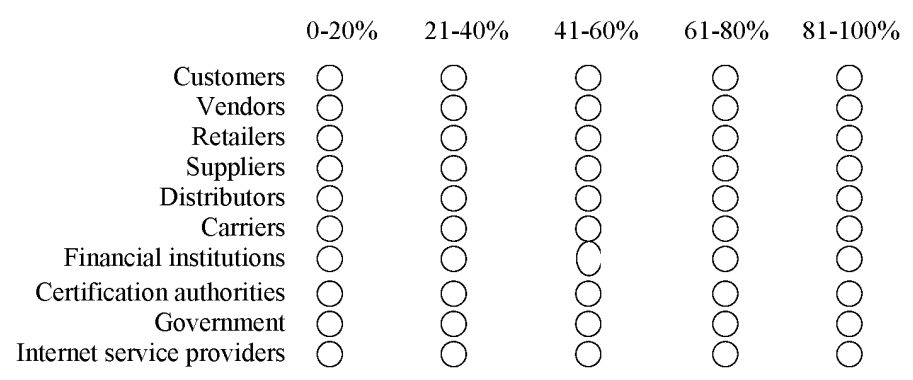

oiintegr In general, the level of integration of your IECS with your internal applications can be qualified as:
Very low
OLow
Moderate
High
Very high

oeintegr In general, the level of integration of your IECS with your business partners can be qualified as
Very low
Low
Moderate
High
Very high

ointegr Please indicate other possible aspects of your IECS's integration level which do not appear among those enumerated above:

iintegr $=$ internal integration $\quad$ eintegr $=$ external integration

oiintegr $=$ open question internal integration oentegr $=$ open question internal integration ointegr $=$ open question integration.

\section{Part E: Types of EC Use and EC Use}

In this section, we would like to know how your organisation uses its IECS and the Internet to support its business activities. ${ }^{5}$ Using the following scale, please indicate the extent to which you agree with each of the following categories of IECS use. Please, circle the number that best represents your opinion. 


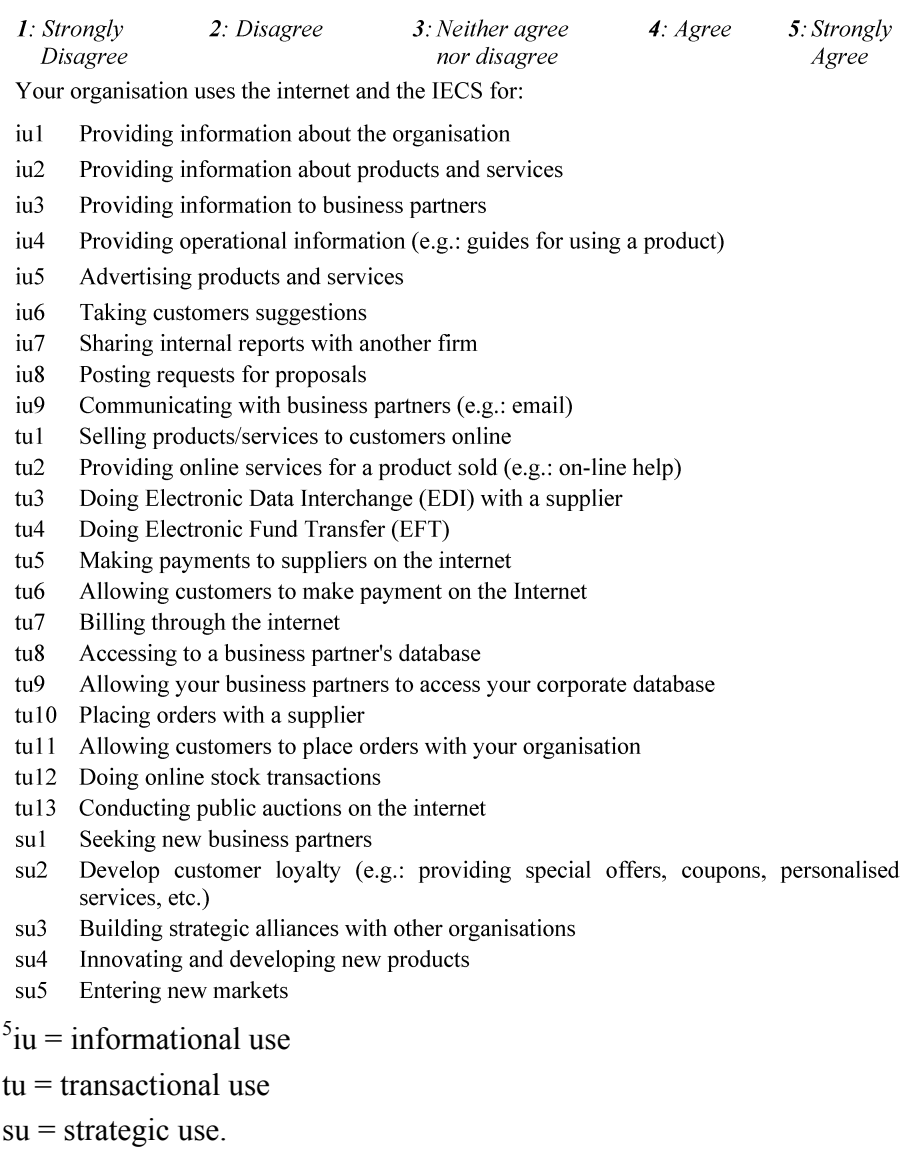

Using the following scale, please indicate the extent to which you agree with each of the following categories of IECS us. ${ }^{6}$ Please, circle the number that best represents your opinion.

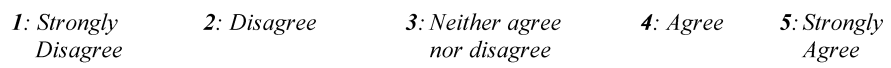

int1 Not using the IECS any more would disadvantage your organisation

int2 Your IECS is used to accomplish usual tasks

int3 The use of the IECS allows the users to have high level of control over the activities of your organisation

int4 The use of the IECS allows to obtain critical information about your organisation

int5 The use of the IECS allows to identify trends and obtain critical information about your organisation's environment

int6 IECS allows users to make strategic decisions

ouse1 In general, the level of use of your IECS can be qualified as being:
$\bigcirc$ very low
Low
Moderate $\bigcirc$ High
Very high

ouse2 Please indicate other possible aspects of your IECS use which do not appear among those enumerated above:

${ }^{6}$ Int $=$ internalisation

ouse $=$ level of use open question. 


\section{Part F: EC Advantages}

In this section, we would like to know the benefits provided by the IECS to your organisation ${ }^{7}$. Using the following scale, please give your perceptions of the benefits generated by the use of the IECS by your organization. Please, circle the number that best represents your opinion.

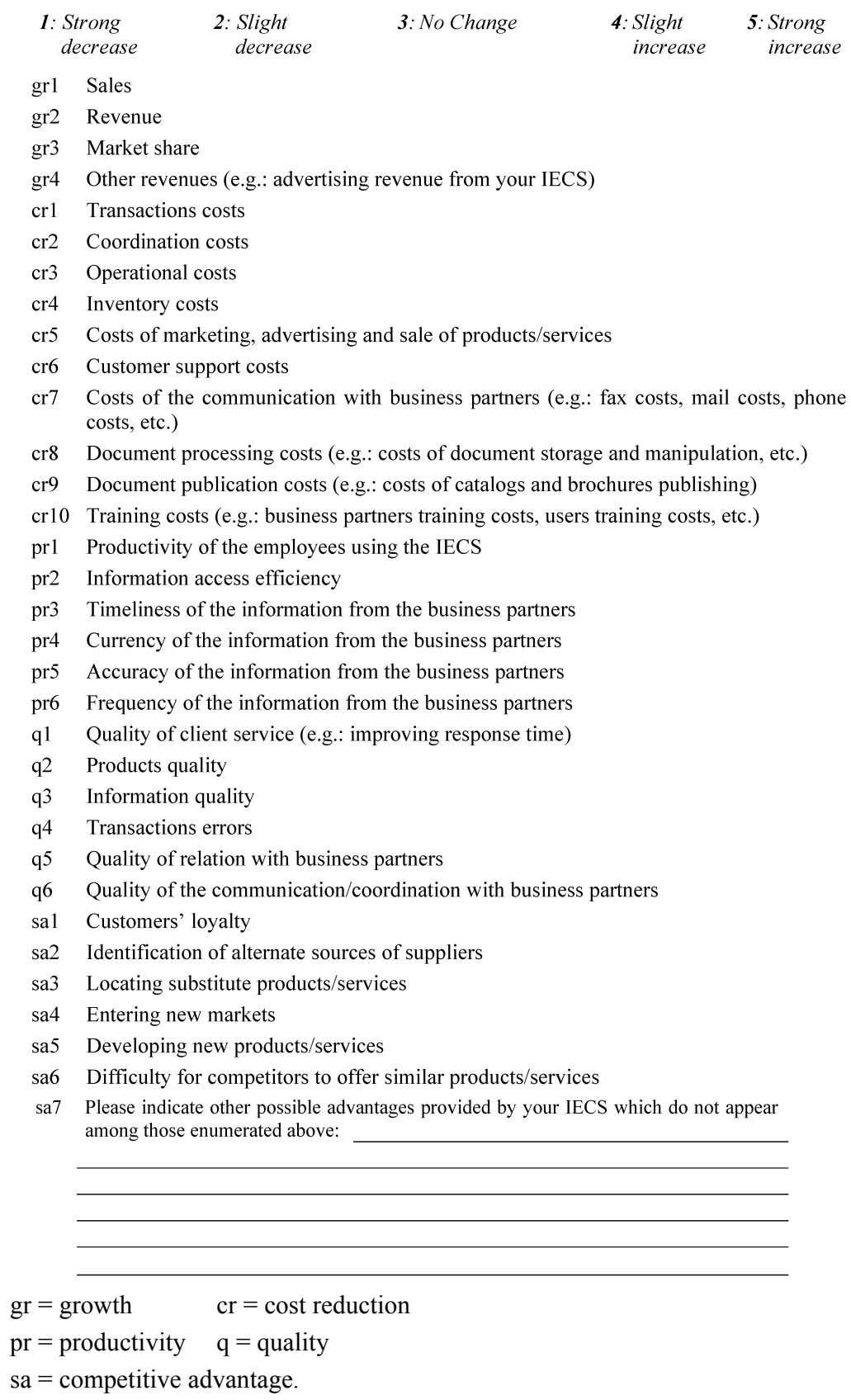




\section{Part G: General Information}

The questions of this section aim to collect general information about the respondent and the organisation.

\section{Information about the organisation}

g1 Please, indicate the name of your organisation (optional):

g2 Please, indicate the number of employees in your organisation:

g3 Please, indicate the activity sector that best describes your organisation:

g4 Please, indicate the revenues of your organisation: \$

g5 Please, indicate the approximate annual budget that is allocated to the activities of electronic commerce on the internet and the World Wide Web: $\$$

g6 Please, indicate the type of internet technology/technologies used for commercial purpose in your organisation (check all the boxes that apply):

$\square$ Email

Search tools

Internet Fax

Internet phone

Newsgroups

IRC (Chat room)

$\square$ Telnet

$\square$ Listserv

$\square$ Intranet

$\square$ Extranet

Site Web

$\square$ Browsers

Other technology (please specify):

\section{$\square$ Electronic catalog}

File Transfer

$\square$ Internet-based Videoconference

$\square$ Internet-based Electronic payment

$\square$ Internet-based Electronic Fund Transfer

$\square$ Internet-based EDI

g7 Please, indicate the type of activities for which your IECS is used (check all the boxes that apply):

$\square$ Activities with consumers

$\square$ Activities with organisation (e.g.: clients, suppliers, distributors, governments, etc.)

Internal Activities

$\square$ Other (please specify):

\section{Information about the respondent}

g8 Please, indicate your name (optional):

g9 Please, indicate your function or your title in the organisation:

g10 Please, indicate your role(s) in the electronic commerce activities within the organisation:

g11 Are you interested in receiving a summary of the results of this study? $\bigcirc$ Yes $\bigcirc$ No If "yes", please, give your email address:

g12 Comments: 